\title{
The Role of a Political Party Website: Lessons Learnt from the User Perspective
}

\author{
Asbjørn Følstad ${ }^{1}$, Marius Rohde Johannessen ${ }^{2}$, and Marika Lüders ${ }^{1}$ \\ ${ }^{1}$ SINTEF, Oslo, Norway \\ \{asbjorn.folstad, marika.lueders\}@sintef .no \\ ${ }^{2}$ Buskerud and Vestfold University College, Horten, Norway \\ marius.johannessen@hbv. no
}

\begin{abstract}
Though substantial research efforts have been spent on understanding the role of political party websites, there is a lack of in-depth knowledge concerning how such webpages are experienced by their users. In this paper, we present an interview study addressing users' experiences of political party websites. Eleven users of a political party website were interviewed to explore their experiences with this website in terms of its features for information, engagement, mobilization, and interaction. The study contributes new understanding of how different features of political party websites affect users' experiences. In particular, our findings shed light on the importance of high-quality informational content in political party websites for user engagement, and the role of features for interaction and dialogue relative to features for information. On the basis of our findings we offer lessons learnt relevant to the design and management of political party websites and suggest future research.
\end{abstract}

Keywords: eParticipation, political party websites, user study.

\section{Introduction}

Political party websites have become important arenas for political communication. Through such websites, political parties can present their message directly to the citizens, mobilize supporters during and between campaigning periods, and engage supporters and adversaries in dialogue and debate [1].

Political party websites are typically seen as one component in an online strategy for communication and mobilization, a strategy which may also encompass unofficial party blogs [2], political candidate websites, general purpose social networking sites, and microblogging. Political party websites may connect to arenas for political debate [3] and offer means for interaction with the electorate [4].

A large number of studies have been conducted on political party behavior online [5], including analyses of the features of political party websites, traffic on such websites, and the correspondence between what is offered and how these websites are being used $[2,3,4],[6]$. Few studies go in depth on how political party websites are experienced by its users [7]; findings of relevance to this topic typically are based on large scale questionnaire studies [8,9]. This lack of in-depth studies on users' 
experiences is noteworthy, given that online political communication is hypothesized to improve citizens' political engagement [6] and participation [3]. Arguably, the degree to which online political communication leads to such increased engagement and participation will depend on how the same communication is experienced by its recipients.

In this paper we present a qualitative study set up to explore how a political party website is experienced by its target group. In particular, we studied how the different features of a political party website are experienced. The findings from this exploration strengthen our understanding of the role political party websites may have for the engagement and political participation of their users. Furthermore, the findings imply lessons learnt of relevance for the management and design of political party websites.

The structure of the paper is as follows. First we summarize relevant background from previous studies of political party websites and online political communication. We then present the research question, method, and results. In the method section, we provide a detailed description of the case of our study. In the discussion we review our findings on the basis of the existing literature and suggest lessons learnt for the design of political party websites.

\section{Background}

\subsection{The Evolution of Political Party Websites}

The role and appearance of political party websites have changed markedly since their first appearance in the nineties. Norris [3] described how the initial online presence of political parties and candidates, in particular in the United States, generated skepticism concerning its ability to strengthen political engagement. Here, mainstream political candidate websites were seen as mainly supporting uni-directional communication, with little opportunity for dialogue. Nevertheless, in her survey of European party websites of the year 2000, Norris found that about half of these offered an opportunity to join online discussion groups and about the same proportion gave access to volunteer services [3].

The Dean campaign of the US Democratic party presidential primary, 2004, has been seen as a turning point concerning the internet as an arena for political engagement, in particular in terms of mobilization [10]. During the last decade, European parties have introduced a wider range of features and functionality in their websites [6], [11]. Today, the online presence of political parties is seen as highly important to political party's ability to inform, engage and mobilize.

\subsection{The Features of a Political Party Website}

Lilleker et al. [6] provide a conceptual framework for analyzing political party websites that is useful for our study. This framework was used in a study of party websites during the 2009 European parliamentary elections. The websites were analyzed according to four distinct feature types: (a) information, (b) engagement, (c) mobilization and (d) interactivity. The concepts underlying these feature types correspond to key topics in the 
literature on online political participation and digital democracy, and are therefore useful as a conceptual framework to study the roles of a political party website.

Information. The information role of political party websites is highlighted by a number of authors [2,3], [11,12]. In particular, political party websites are seen as arenas for direct communication from the party to the citizens, where the party does not have to communicate through the editorial filter of newspapers, radio or television [10]. Such direct communication has been suggested to be of particular value to minor political parties with limited resources [3].

Website Engagement. Increased political engagement may be seen as the ultimate goal of using the web for political communication. In particular in the light of the decline in political interest and organization observed the last few decades [3], [13]. In the conceptual framework of Lilleker et al. [6], the term engagement is used in reference to those features of a political party website that are designed to support engagement with the website, such as video, music, pictures, and animations. In particular, such engagement features can be beneficial for the website's persuasive ability. In this paper we refer to this concept as website engagement, and discuss users' political engagement as something distinct, or in addition to, engagement driven by website engagement features.

Mobilization. Mobilizing features are understood as functionality that allow webpage visitors to join the party, make donations, or engage in campaigning activities. The value of mobilizing through political candidate or party websites has in particular been made visible in United States presidential and primary campaigns [10]. Functions for mobilization have also increasingly been taken up by European political parties [3], [11], [14].

Interaction and Dialogue. The promise of increased political participation, induced by early thinkers on the political implications of the web, have led to an aim for political party websites to be more than one-way information channels [3], [15]. Norris [3] highlights the potential of political party websites as arenas for dialogue. In the conceptual framework of Lilleker et al. [6], interaction and dialogue (termed interactivity by Lilleker et al.) concerns website functionality that support dialogue between the party and the citizens, such as discussion forums open to party officials and citizens alike.

\subsection{Approaches to the Study of Political Party Websites}

Previous studies on political party websites follow a variety of methodological approaches. A number of studies involve content analysis of political party websites and associated online material [3,4,5], [15]. Others involve network analysis [16] and analyses of website traffic data [2] to map online networks and behavior on online political websites. Yet others use surveys to map citizens' high level usage and preference for political party websites [9] or present interview data from party officials [12], [14]. Some of the studies utilize a combination of different methodological approaches [2].

We are aware of only one previous study, by Baxter and Marcella [7], that go in depth on how political party websites are experienced by their users. This study 
provided insight in the need for concise and updated information on party policies and candidates, in particular on the local level, as well as insight in users' views on negative campaigning and politicians use of social media.

From questionnaire studies [2], [9] we have some insight in the high level experiences and preferences of the users of political party websites. Nevertheless, such questionnaire studies do not provide in-depth understanding of why these experiences have come into being and how they may be changed, due to absence of in-depth qualitative data.

\section{Research Question}

Given the assumed potential for political engagement held by political party websites, we are intrigued by the current lack in research concerning how such websites are experienced by its users. We apply the framework provided by Lilleker et al. [6], and propose the following research question:

How is a political party website experienced by its users? In particular, how is the website experienced in terms of its informational content, website engagement features, mobilization features, and features for interaction and dialogue?

The research question was framed so as to target the actual users of the website, rather than citizens in general.

\section{$4 \quad$ Method}

To make a focused exploration of how a political party website is experienced by its users, we conducted the study in the context of the website of one of the main political parties in Norway. To gain access to the experiences of the users, we conducted the data collection as a series of interviews.

\subsection{Case and Participant Selection}

The political party website of our case was particularly relevant to address our research question, as it is set up to accommodate all the four types of website features addressed by Lilleker et al. [10]. The main landing page of the party website resembled any other party website, with features for information, engagement, and mobilization. The party website also included an extensive set of webpages for interaction and dialogue. Some of these webpages concerned local party bodies, others were thematically oriented (concerning themes such as health, employment, education, and integration), yet others concerned political training and additional support for mobilization.

Choosing as our case a Norwegian political party website was beneficial in several respects. Firstly, the high internet penetration in Norway, where $94 \%$ of all households have internet access as of 2013 [17], makes political party websites available for 
practically everyone irrespective of age, education, and income. Secondly, the high penetration of social media in Norway, where $63 \%$ of the population visit Facebook daily as of 2013 [18], makes website features for interaction and dialogue particularly relevant. Thirdly, the relatively egalitarian Norwegian society [19] may indicate relatively low thresholds for taking part in interaction and dialogue, which is important for the study of experiences concerning website features for interaction and dialogue.

We invited potential participants to our interview study on the basis of their presence in open groups at the party website. We selected our invitees among people associated with the groups of one or more of five local party bodies. For a person to be invited he or she had to have visited the interaction and dialogue pages of the party website at least once the last 30 days, and not be responsible for any of the party webpages or groups. In total 106 invitations were sent out as personal messages via the party webpage. In the invitations we informed about the purpose of the study, the study administrators, and the privacy policy for the study (such as data management, confidentiality and anonymization, as well as the voluntarity of participation and opportunity to withdraw from the study at any point in time).

We conducted interviews with 11 users of the party website; four female and seven male. Average age was 45 years $(S D=15 ; \min =25$; $\max =72)$. Eight of the participants used the political party website weekly or more. Eight had used the political party website for less than a year.

\subsection{The Interview and Analysis Process}

The data collection was conducted as semi-structured interviews. The participants were interviewed individually, and the maximum duration of the interviews was 1.5 hours. The interview followed an interview guide targeting the participant's use of the political party website, reasons for visiting, recall of the participant's last visit, positive and negative experiences, causes of engagement, suggested changes, and suggestions for the party's use of the web site in the coming election period. The interview session also included time to browse the website together with the interviewer, which helped the participant provide additional details and also served to uncover possible usability issues in the webpage.

The interviews were taped following the participants informed consent. When all interviews were completed, they were transcribed and analyzed. The analysis was conducted as a content analysis [20], where each interview transcript was analyzed in terms of the four types of political webpage features of Lilleker et al. Following this, the data associated with each feature type were reviewed for common or diverging patterns.

\section{$5 \quad$ Results}

\subsection{Information}

The participants described the political party website as a source of useful and relevant information. They reported to appreciate both static informational content, such as content concerning the political platform of the party, and content of relevance for ongoing events or thematic debates. 
M72: For example at the last national meeting there were a lot of presentations you could access. [...] This is a great system. If you have the time, there is no end to the information you can get.

The participants pointed out that the informational content of the party website often is used as part of a broader reading process. For example, when reading about a particular news topic in a newspaper, they might update themselves on the relevant party arguments and standpoints via the party website. Thus, an important role for the informational content on the party webpage may be to supplement news content from other sources and, thereby, provide the party perspective.

M45: Concerning the choice of fighter planes [...] when I started reading about our choice of the Joint Strike Fighter I, I had to, okay, what are the alternatives. [...] And then I had to go back to the party website to refresh my memory on what we used as arguments.

Informational content of relevance to the local party level was seen as particularly desirable by the participants. However, they reported local content often to lack the richness and updated character as they were used to in the content administered centrally, something that was reported as disappointing.

M39: [...] In particular what happens locally. But then, the user experience is somewhat limited concerning what is available of local news. Such as for the webpages of my local party organization there is nothing.

Some of the participants pointed out that the informational content at times is structured and presented in a manner that is difficult to use. This may be due to the informational content being contributed by a large number of authors belonging different local party bodies, and that the information concerns local, national, and international themes. Currently, the central party administration only edits the central parts of the party webpage. A more centralized editorial function throughout the party webpage would have reduced these difficulties, but would at the same time hinder the bottom-up contributions that the website is meant to facilitate.

M25: When no one filters the information, as in an editorial team, it is fully up to the user to judge what the text says. [...] This makes me more critical concerning which texts I prioritize to read.

\subsection{Website Engagement}

The participants all described themselves as politically engaged, and nearly all reported that their use of the political party website was driven by this engagement. Though some argued that the party website, in turn, could increase their political 
engagement the main rule seemed to be that regular use of the party website was engagement-driven - not driven by website engagement features. Thus, prototypical website engagement features, such as pictures or videos, were not seen by the participants as critical to build or sustain their political engagement.

M51: I do get engaged by what I am already engaged in, that is, political issues or people that mean something to me, when they are there and tell about something this engages me. [...] But this is because I have a political engagement.

A few of the participants did report that they saw the benefit of website engagement features. In particular, such features were seen as useful in the context of campaigning. Most participants, however, did not highlight such website engagement features as important for their experience of the website. Rather, they claimed informational content presented in an engaging and easy to find manner to be the most important way that the website could support engagement.

Thematic informational content was seen as particularly engaging to the participants, such as content concerning particular issues in health politics, welfare or employment. The participants typically reported their political engagement to be closely tied to a few thematic areas, and that informational content, or debates, on these areas in particular could be experienced as engaging.

F32: [My preference for content] depends on the theme, whether it is a theme I am interested in or not. And if I am interested, a long presentation may be just as interesting as a short one.

Some of the participants argued that for informational content to be engaging it needs to offer a clear perspective, so that it can be seen as a contribution to a larger debate. Neutral informational content is argued to be the domain of the newspapers. Posts and comments formulated in a blend and neutral manner was seen as working against engagement.

The one website engagement feature that was seen as useful by nearly all the participants was email notifications on newly published content. Most of the participants reported such notifications often to be the reason why they visited the party website; without these they would have visited the party website far less frequently.

F36: It is those emails that make me go [to the website] and check. I only very rarely go to check if not.

\subsection{Mobilization}

The party website was reported to hold a mobilization potential to the participants mainly in two ways: By providing information on upcoming party meetings and by providing information on available training and courses. Information concerning party meetings was seen as particularly useful. Information concerning available training and courses were seen as important to increasing one's own engagement within the party. 
F32: It seems like they also take good care of people who want to volunteer to engage more people. This concern for training and schooling is very positive.

Some of the participants argued that the webpages could have been used more efficiently for mobilization at a local party level, and that several local bodies still seemed to rely too much on traditional means of mobilization and not take sufficient advantage of the opportunities offered by the party website.

M45: I was somewhat disappointed when I found out that [my local party body] did not publish meetings online, or enter events in the online calendar or anything. But, of course, I am also obliged to seek such kind of information myself. But it would have been very easy if they just had put it online.

At the end of the interviews, we asked the participants how they would like the party websites to be used during the upcoming campaign period. The participants held that the centrally administered pages of the party webpage could be an important part of a successful campaign, though it was argued that traditional campaigning would be more important than online campaigning also in the near future. Local party webpages were seen as less relevant for campaigning as it was argued that these would require more resources and competency than what was available for most local party bodies.

M38: I think that by no means [the party webpage] can replace work in the field. But it may be an addition to this field work. The problem may be that you mostly reach your own through the party webpage.

\subsection{Interaction and Dialogue}

Though all the participants had some experience with the features for interaction and dialogue, only two participants regularly used these. These two reported to do so because they were engaged in the topics under debate and wanted to have an impact in the discussion.

Features for dialogue spark off expectations for replies, preferably from partymembers in decision-making positions. As lamented by M70, experiences with participating do not always live up to expectations. In this example, he refers to a contested decision with conflicting interests between industry needs and environmental concerns, where he believes the party had taken a stance in conflict with the grassrootlevel of the party.

M70: And this issue, I am somewhat upset concerning this. [...] I started a discussion on this to see what kind of response I would get. But, okay, it went as it had to, I am old enough in this game to understand that. But at the same time others reading this might get an eye-opener. 
The experiences of the two participants who used the features for dialogue regularly are aligned with the experiences of those who did not use these features much. Three main reasons were offered concerning own or others' lack in active participation through interaction and dialogue.

Firstly, some participants reported to be uncertain of the possible consequences of participating in a debate. Such uncertainty concerned, for example, the degree to which comments should be aligned with the party political platform, or whether opinions in a political discussion online could be in conflict with the participants' other roles in society.

F36: If I was to say anything in an online debate on [this particular issue] I would have to, as I am relatively new in the party, check what I was about to write with others in the party.

Secondly, some argued that debates were typically too bland to be engaging. Posts and comments were perceived not to be sufficiently pointed to be interesting.

M39: You can of course follow [content published by] key politicians, but I find much of their contributions just to be recirculated opinions. I do not even bother to read all of that.

Thirdly, some reported that they saw online debate at more politically neutral arenas, such as the debate sections of online newspapers, as more relevant. Though the features for interaction and dialogue of the studied party website were open to anyone, it was held that politically neutral arenas might include more varied voices and marked differences in opinion and, therefore, be more engaging both for the active debaters and the observing bystanders.

M25: I do not really bother about what the debaters say at the party website. This may sound strange, but they are all inclined to support this particular party. Then you do not get a real debate, like. Then I find it more interesting to read the newspapers.

\section{Discussion}

\subsection{The Role of the Political Party Website}

The presented results provide new insight into the role of a political party website by helping us understand how the different features of such a website might affect users' experiences. One noteworthy finding is that the same website may be experienced differently, and thus hold different roles, for different users. This is, in particular, seen for features concerning interaction and dialogue where some participants use the opportunity provided by the party webpage to engage in online debate, others only observe others contributions to the debate, and yet others just disregard the opportunity for debate. This variation in the roles that a political webpage may hold for different users highlights the need for a nuanced framework of website features, such as that of Lilleker et al. [4], to conceptualize this variation. 
The role of a political party website for a given user also depends on his or her thematic preferences. Practically all the participants reported that their political engagement was linked to particular topics. From previous studies we know that the informational content of political party websites is important [2,3], [11,12]. This study supplements this knowledge by addressing the need to match the informational content to the specific thematic interests of the users.

We find that though a political party website offers features for website engagement, mobilization, and interaction and dialogue, the user's experience of the website is strongly determined by the degree to which relevant and interesting informational content is easily available. This finding is similar to that made by Baxter and Marcella [7], who highlighted the importance of updated and concise informational content.

Our study participants argue that their use of the political party website is driven by their political engagement, and that this engagement is best fed by the availability of well-crafted informational content. For the bulk of our participants, the main role of the political party website is to provide relevant and interesting information, thereby contributing the party perspective or opinion on relevant themes or issues. This finding complements the perspective of Norris [3] who argued that the democracyenhancing role of political party websites might be diminished if their only purpose is to contribute uni-directional information.

In our study, it is particularly thought-provoking that the party webpage is experienced to provide limited room for conflicting and diverging opinions. More knowledge is needed on the causes for, and extent of, this perceived limitation in the interaction and dialogue of political parties. One possible cause for this limitation may be individual users' uncertainty and sense of vulnerability when participating in online interaction and dialogue, something that may be strengthened by the relative novelty of such features in political party websites.

\subsection{Lessons Learnt}

The findings offer useful lessons learnt for the management and design of political party websites, concerning each of the four addressed types of website features. Above all, it is important to notice the need to balance the party website as a space where users can be informed about the politics of the party with the need to provide more space and leeway also for diverging and conflicting opinions.

Information features are critical to a political party website; likely the most important feature type for most users. Informational content needs to be structured in a manner that fits the main thematic interests of its users. Furthermore, to serve its purpose as a complement to other online informational content, such as that of online newspapers, the informational content on political party webpages needs to provide a marked perspective or opinion. Local informational content is important, as this is closely linked to the users' political engagement. Nevertheless, it may be challenging to administer local content so that it is perceived as well-crafted and relevant for the user, possibly due to a lack in dedicated local resources. It will be important to rethink how local informational content is to be produced and maintained. 
Website engagement features are second in importance to informational features; at least for regular users of a political party website. This is not to say that website engagement features such as images and videos may not be important to sporadic visitors; in particular, in the context of campaigning. Nevertheless, well-crafted informational content clearly arguing for the perspective of the party is reported to be more important to the user's experience of the website. For sporadic visitors, high level informational content may possibly be an important driver of engagement, as such visitors will need to get a quick overview of the party opinion on political themes of particular relevance for them. Email notifications may be important to bring regular users to new informational content.

Mobilization features are potentially important to regular users of political party websites, in particular for meetings and training opportunities. However, until most party members are regular users of the party website, such features may have to be paralleled by traditional means of information, to make sure that one reaches a sufficient proportion of the intended recipients. Features concerning funding were not at all discussed by our participants. Features concerning mobilization for campaign work were not much discussed either; possibly in consequence of our participants not being part of a party administration in charge of such campaign mobilization.

Interaction and dialogue features are interesting to some, but not all, of the interviewees. It is worthy of notice that such features are seen as relevant also for some of those that do not themselves use these actively. Hence, such features should be set up so as to be relevant also for non-active users. The design of interaction and dialogue features should be done with care, and the purpose of such features needs to be clearly communicated to the users. These features might benefit from having an informal character to signal that contributions can be written and read as spontaneous comments in an engaged dialogue; without differences in opinion there will be no debate.

\subsection{Limitations and Future Work}

The presented study has generated valuable insight concerning how a political party website is experienced by its users. Yet, given the limited scale and the focus on one party webpage only, the study would benefit from being repeated for a wider range of political parties and contexts - for example within other countries than Norway. We suggest, for future work, the continued use of the framework of Lilleker et al [6] to improve our understanding of what different webpage features means for the webpages' role as platforms to support democracy. Such future studies would also benefit from triangulating interview data with some of the more frequently used data sources for the study of political party websites; in particular, analyses of webpage content and questionnaire studies. The study of users' experiences of political party webpages is important to understand the role of such webpages in a living democracy. We hope our study may motivate future research to continue this endeavor.

Acknowledgement. This work was conducted as part of the research project NETworked Power and finalized within the research project delTA; both projects supported by the VERDIKT program of the Norwegian Research Council. 


\section{References}

1. Vergeer, M., Hermans, L., Cunha, C.: Web campaigning in the 2009 European Parliament elections: A cross-national comparative analysis. New Media \& Society 15(1), 128-148 (2013)

2. Gibson, R.K., Gillan, K., Greffet, F., Lee, B.J., Ward, S.: Party organizational change and ICTs: The growth of a virtual grassroots? New Media \& Society 15(1), 31-51 (2013)

3. Norris, P.: Preaching to the Converted? Pluralism, Participation and Party Websites. Party Politics 9(1), 21-45 (2003)

4. Lilleker, D.G., Malagón, C.: Levels of Interactivity in the 2007 French Presidential Candidates' Websites. European Journal of Communication 25(1), 25-42 (2010)

5. Cardenal, A.S.: Why Mobilize Support Online? The Paradox of Party Behaviour Online. Party Politics 19(1), 83-103 (2013)

6. Lilleker, D.G., Koc-Michalska, K., Schweitzer, E.J., Jacunski, M., Jackson, N., Vedel, T.: Informing, Engaging, Mobilizing or Interacting: Searching for a European Model of Web Campaigning. European Journal of Communication 26(3), 195-213 (2011)

7. Baxter, G., Marcella, R.: Online Parlimentary Election Campaigns in Scotland. eJournal of eDemocracy and Open Government 5(2), 107-127 (2013)

8. Følstad, A., Lüders, M.: Online Political Debate: Motivating Factors and Impact on Political Engagement. In: Wimmer, M.A., Tambouris, E., Macintosh, A. (eds.) ePart 2013. LNCS, vol. 8075, pp. 122-133. Springer, Heidelberg (2013)

9. Lusoli, W., Ward, S.: Digital Rank - and - file: Party Activists' Perceptions and Use of the Internet. The British Journal of Politics \& International Relations 6(4), 453-470 (2004)

10. Hindman, M.: The Myth of Digital Democracy. Princeton University Press, Princeton (2008)

11. Lilleker, D.G., Jackson, N.A.: Towards a More Participatory Style of Election Campaigning: The Impact of Web 2.0 on the UK 2010 General Election. Policy \& Internet 2(3), 69-98 (2010)

12. Lüders, M., Følstad, A., Waldal, E.: Expectations and Experiences with MyLabourParty: From Right to Know to Right to Participate? Journal of Computer-Mediated Communication, Article First Published Online (2013), doi:10.1111/jcc4.12047

13. Stromer-Galley, J., Wichowski, A.: Political Discussion Online. In: Consalvo, M., Ess, C. (eds.) The Handbook of Internet Studies, pp. 168-187. Wiley-Blackwell, Oxford (2011)

14. Karlsen, R.: Obama's Online Success and European Party Organizations: Adoption and Adaptation of US Online Practices in the Norwegian Labor Party. Journal of Information Technology \& Politics 10(2), 158-170 (2013)

15. Jackson, N.A., Lilleker, D.G.: Building an Architecture of Participation? Political Parties and Web 2.0 in Britain. Journal of Information Technology \& Politics 6(3-4), 232-250 (2009)

16. Johannessen, M.R., Følstad, A.: Political Social Media sites as Public Sphere: A Case Study of the Norwegian Labour Party. Communications of the Association for Information Systems 34(56), 1067-1096 (2014)

17. Statistics Norway: ICT Usage in Households, 2nd edn. (2013), http://ssb.no/en/teknologi-og-innovasjon/statistikker/ikthus

18. TNS Gallup: Social Media Tracker (2013), http: / / www. tns-gallup.no/ ?did=9107535

19. Østerud, Ø.: Introduction: The peculiarities of Norway. West European Politics 28(4), 705-720 (2005)

20. Ezzy, D.: Qualitative Analysis: Practice and Innovation. Routledge, Oxon (2002); Parliament elections: A cross-national comparative analysis. New Media \& Society 15(1), $128-148$ (2013) 